\title{
Drug resistance reversed by silencing LIM domain-containing protein 1 expression in colorectal carcinoma
}

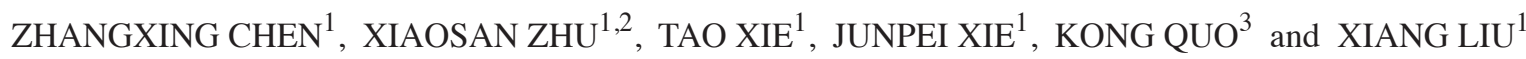 \\ ${ }^{1}$ Department of Gastroenterology, The 174th Hospital of the PLA; ${ }^{2}$ Department of Gastroenterology, \\ Chenggong Hospital, Xiamen University, Xiamen, Fujian 361003; ${ }^{3}$ Center for Clinical and Translational Science, \\ Creighton University School of Medicine, Omaha, NE 68178, USA
}

Received October 6, 2013; Accepted March 20, 2014

DOI: $10.3892 / \mathrm{ol} .2014 .2155$

\begin{abstract}
The role of LIM domain-containing protein 1 (LIMD1) in the multidrug resistance of colorectal carcinoma (CRC) has not yet been established. The aim of the current study was to investigate the chemosensitivity of CRC multidrug-resistant (MDR) cells following the silencing of LIMD1. The MDR phenotypic Colo205 and HCT-8 cell lines were examined, which were established by exposure to increasing doses of 5-fluorouracil (5-FU) over a period of one year. LIMD1 siRNA constructs were transfected into CRC MDR cells and the phenotypic effects were determined comprehensively. The Colo205 and HCT-8 cell lines were more resistant to 5-FU compared with their respective parental cell lines. In addition, the two MDR cell types expressed significantly more LIMD1 compared with their parental lines. The stably transfected cells showed various degrees of reversal of the MDR phenotype, and 5-FU-induced apoptosis was increased in the transfected cells compared with the controls. In conclusion, RNA interference targeting LIMD1 may present a novel therapeutic option for CRC.
\end{abstract}

\section{Introduction}

Colorectal carcinoma (CRC) is the second leading cause of cancer-related mortality worldwide (1). Although, surgical intervention is no longer the only treatment option and chemotherapy presents an important strategy for the treatment of the majority of CRC patients (2). However, de novo and acquired resistance to a variety of drugs is common and, therefore, the drug-resistant phenotype of CRCs presents one of the major obstacles in its eradication (3).

Gene silencing or inhibition of associated downstream proteins is commonly used to understand gene function (4). If

Correspondence to: Dr Zhangxing Chen, Department of Gastroenterology, The 174th Hospital of the PLA, 96 Wenyuan Road, Xiamen, Fujian 361006, P.R. China

E-mail: chenzx174@sohu.com

Key words: apoptosis, colorectal carcinoma, multidrug resistance, LIM domain-containing protein 1 multidrug resistance in CRC cells is found to correlate with LIM domain-containing protein 1 (LIMD1) expression, it may be possible to reverse drug resistance by interfering with the expression of this protein, thus providing a potential treatment for CRC. This is an attractive option since drugs that selectively inhibit LIMD1 in CRC are in the early phase of development and little, if any, evidence exists regarding the effects of blocking LIMD1 in CRC. RNA interference is a post-transcriptional gene silencing mechanism in which mRNA is degraded in a sequence-specific manner (5). The aim of this study was to demonstrate that the specific silencing of LIMD1 by RNA interference may effectively reverse drug resistance in multidrug-resistant (MDR) CRC cells by enhancing cell apoptosis, which may highlight novel investigational targets that will provide therapeutic options for CRC.

\section{Materials and methods}

Experimental approval. The study was conducted in accordance with the Declaration of Helsinki. All experimental protocols were approved by the Review Committee for the Use of Human or Animal Subjects of Xiamen University (Xiamen, China).

Cell culture and induction of MDR. The human CRC Colo205 and HCT-8 cell lines were purchased from the Cell Bank of Shanghai Institute of Biochemistry and Cell Biology, Chinese Academy of Sciences (Shanghai, China). The cell lines were cultured in Dulbecco's modified Eagle's medium (Hyclone, Logan, UT, USA) supplemented with $10 \%$ fetal bovine serum (Hyclone) at $37^{\circ} \mathrm{C}$ in a humidified atmosphere of $5 \% \mathrm{CO}_{2}$. The 5-fluorouracil (5-FU)-resistant human CRC cell sublines (Colo205/5-FU and HCT-8/5-FU) were established by adding 5-FU [Shanghai Pharmaceutical (Group) Co., Ltd., Shanghai, China] to GIBCO ${ }^{\circledR}$ RPMI-1640 medium (Invitrogen Life Technologies, Carlsbad, CA, USA) at concentrations ranging between 0.01 and $2 \mu \mathrm{g} / \mathrm{ml}$.

siRNA transfection. siRNA was purchased from Thermo Fisher Scientific (Waltham, MA, USA). The Colo205/5-FU and HCT- 8 cells were seeded at a density of $5 \times 10^{4}$ cells/well in six-well plates for $24 \mathrm{~h}$ prior to transfection. The cells were transfected with 25,50 or $75 \mathrm{nM}$ concentrations of 
Table I. Establishment of two 5-FU-resistant colorectal carcinoma sublines.

\begin{tabular}{|c|c|c|c|c|c|c|}
\hline \multirow[b]{2}{*}{ Agents } & \multicolumn{2}{|c|}{$\mathrm{IC}_{50}(\mathrm{mg} / \mathrm{l})$} & \multirow[b]{2}{*}{ RI } & \multicolumn{2}{|c|}{$\mathrm{IC}_{50}(\mathrm{mg} / \mathrm{l})$} & \multirow[b]{2}{*}{ RI } \\
\hline & Colo205 & Colo205/5-FU & & HCT-8 & HCT-8/5-FU & \\
\hline 5-FU & $0.0113 \pm 0.011$ & $0.2719 \pm 0.002$ & 29.21 & $0.0056 \pm 0.018$ & $0.1931 \pm 0.001$ & 16.04 \\
\hline 1-OHP & $0.0061 \pm 0.004$ & $0.1129 \pm 0.005$ & 17.13 & $0.0097 \pm 0.004$ & $0.1101 \pm 0.062$ & 10.21 \\
\hline
\end{tabular}

HCT-8/5-FU cells were 16.04 times more resistant to 5-FU, and Colo205/5-FU cells were 29.21 times more resistant in comparison with the parental cells. HCT-8/5-FU and Colo205/5-FU cells also exhibited cross-resistance to other common chemotherapeutic agents, including 1-OHP. $\mathrm{IC}_{50}, 50 \%$ inhibitory concentration; 5-FU, 5-fluorouracil; 1-OHP, 1-oxaliplatin; RI, resistance index.

siRNA-LIMD1 using Lipofectamine 2000 (Invitrogen Life Technologies) following the manufacturer's instructions.

Western blot analysis. The silencing effects of siRNA targeting the LIMD1 gene were assessed by western blot analysis. The cells were cultured in a six-well plate at a density of $2.0 \times 10^{4}$ cells/well for $48 \mathrm{~h}$, harvested, washed twice with ice-cold phosphate-buffered saline and then lysed in radioimmunoprecipitation assay buffer (Abcam, Cambridge, UK). The cell lysates were briefly sonicated (Sonicator Q700; Qsonica, LLC, Newton, CT, USA) and kept in ice-water for $30 \mathrm{~min}$. The protein concentrations were determined using a BCA Protein Assay kit (Bio-Rad, Hercules, CA, USA). The protein bands were visualized by chemiluminescence using enhanced chemiluminescence plus western blotting reagent (GE Healthcare, Little Chalfont, UK), followed by exposure to Fujifilm LAS-1000 equipment (Fujifilm, Tokyo, Japan). The parallel membranes were incubated with 1:10,000 rabbit anti-human monoclonal antibodies against $\beta$-actin (Santa Cruz Biotechnology, Santa Cruz, CA, USA) and horseradish peroxidase-coupled rabbit anti-mouse monoclonal secondary antibody (Innova Biosciences, Ltds., New York, NY, USA).

Cell growth and chemosensitivity. The chemosensitivity resulting from the LIMD1 knockdown was assessed using an MTT-based cell growth determination kit (Sigma-Aldrich, St. Louis, MO, USA). The sensitivity of transfected CRC cells to the commonly used anticancer drugs, 5-FU and 1-oxaliplatin (Changsha Huir Biological-tech Co., Ltd., Changsha, China), was detected in accordance with a previous study (6). The total cells were then harvested at 12, 24, 36, 48 and $60 \mathrm{~h}$ following drug exposure. The absorbance was measured at $490 \mathrm{~nm}$ using a microplate reader (Getein Biotechnology Co., Ltd., Nanjing, China) and the value of $50 \%$ inhibitory concentration $\left(\mathrm{IC}_{50}\right)$, defined as the drug concentration required to reduce cell survival to $50 \%$ as determined by the relative absorbance of BrdU, was assessed by probit regression analysis. The resistance index (RI) was calculated using the following formula: $\mathrm{RI}(\%)=\left(\mathrm{IC}_{50}\right.$ of treated cells//C $\mathrm{IC}_{50}$ of untreated or parental cells) x 100.

Apoptosis detection assay. The apoptosis detection assay was performed to determine the effects of LIMD1 knockdown on apoptosis in CRC in response to chemotherapy agents. The Colo205/5-FU and HCT-8/5-FU cells were transfected as previously described. The transfected cells and controls
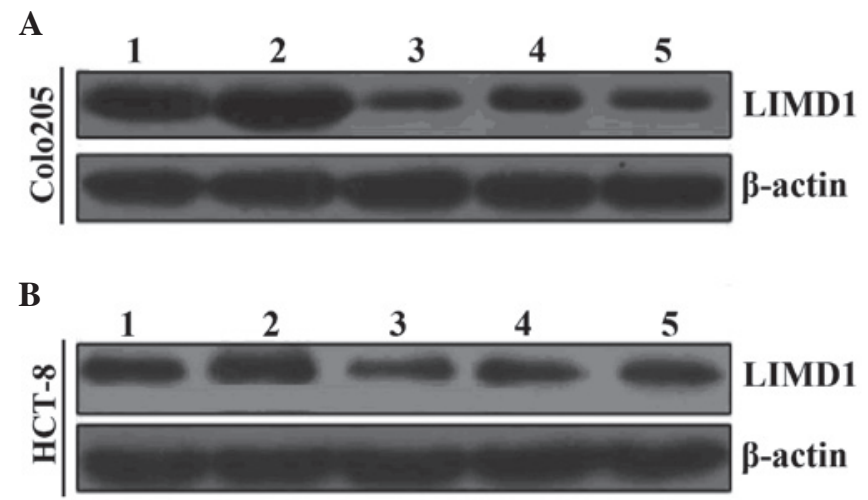

Figure 1. Expression of proteins in multidrug-resistant cells. (A) LIMD1 proteins in Colo205/5-FU cells. The expression of LIMD1 was markedly reduced following treatment with siLIMD1. (B) LIMD1 proteins in HCT-8/5-FU cells. A similar effect was observed in HCT-8/5-FU sublines subjected to siLIMD1 silencing. Lane 1, Parental cells; lane 2, 5-FU-resistant cells; lane 3, $25 \mathrm{~nm}$ siRNA-transfected cells; lane 4, $50 \mathrm{~nm}$ siRNA-transfected cells; lane 5, $75 \mathrm{~nm}$ siRNA-transfected cells. LIMD1, LIM domain-containing protein 1; 5-FU, 5-fluorouracil

were then exposed to $0.2 \mu \mathrm{g} / \mathrm{ml}$ of 5 -FU for $48 \mathrm{~h}$, harvested by trypsinization and centrifuged at $2,000 \mathrm{x}$ g for $5 \mathrm{~min}$ at $4^{\circ} \mathrm{C}$. Next, $0.5 \mu \mathrm{g} / \mathrm{ml}$ of Annexin V-fluorescein isothiocyanate (Becton-Dickinson, Franklin Lakes, NJ, USA) and $0.6 \mu \mathrm{g} / \mathrm{ml}$ of propidium iodide (Shanghai QF Biosciences Co., Ltd., Shanghai, China) were added to the cell suspension. After $15 \mathrm{~min}$, the stained cells were immediately analyzed by BD FACSCalibur ${ }^{\mathrm{TM}}$ (BD Biosciences, San Jose, CA, USA).

Statistical Analysis. Differences between the groups were analyzed by one-way analysis of variance using Dunnett's post hoc test for continuous variables and the $\chi^{2}$ or Fisher's exact tests for categorical variables, as appropriate. $\mathrm{P}<0.05$ was considered to indicate a statistically significant difference. Data were analyzed using SPSS 17.0 (SPSS, Inc., Chicago, IL, USA) and presented as the mean \pm standard deviation.

\section{Results}

Establishment of MDR CRC cell lines. The Colo205/5-FU cells were 29.21 times more resistant to 5-FU compared with the Colo205 cells, and the HCT-8/5-FU cells were 16.04 times more resistant when compared with the HCT- 8 cells. The two cell lines also exhibited cross-resistance to another common chemotherapeutic agent, 1-oxaliplatin (Table I). 
Table II. Restoration of drug sensitivity following the knockdown of LIMD1 by RNA interference resensitized 5-FU-resistant colorectal carcinoma sublines to the applied agents ( $\mathrm{n}=$ five per group).

\begin{tabular}{|c|c|c|c|c|c|c|}
\hline \multirow[b]{2}{*}{ Agents } & \multicolumn{2}{|c|}{$\mathrm{IC}_{50}(\mathrm{mg} / \mathrm{l})$} & \multirow[b]{2}{*}{ RI } & \multicolumn{2}{|c|}{$\mathrm{IC}_{50}(\mathrm{mg} / \mathrm{l})$} & \multirow[b]{2}{*}{ RI } \\
\hline & Colo205/5-FU & Colo205/5-FU/siLIMD1 & & HCT-8/5-FU & HCT-8/5-FU/siLIMD1 & \\
\hline $5-\mathrm{FU}$ & $0.2657 \pm 0.003$ & $0.0608 \pm 0.033$ & 1.23 & $0.1181 \pm 0.002$ & $0.0108 \pm 0.006$ & 1.09 \\
\hline 1-OHP & $0.0062 \pm 0.004$ & $0.0112 \pm 0.003$ & 2.32 & $0.0098 \pm 0.004$ & $0.0149 \pm 0.003$ & 1.78 \\
\hline
\end{tabular}

Compared with the untreated parental cells, the highly 5-FU-resistant Colo205/5-FU and HCT-8/5-FU cells were almost completely reversed to an 5-FU-sensitive phenotype. LIMD1, LIM domain-containing protein 1; $\mathrm{IC}_{50}, 50 \%$ inhibitory concentration; 5-FU, 5-fluorouracil; 1-OHP, 1-oxaliplatin; RI, resistance index.

A

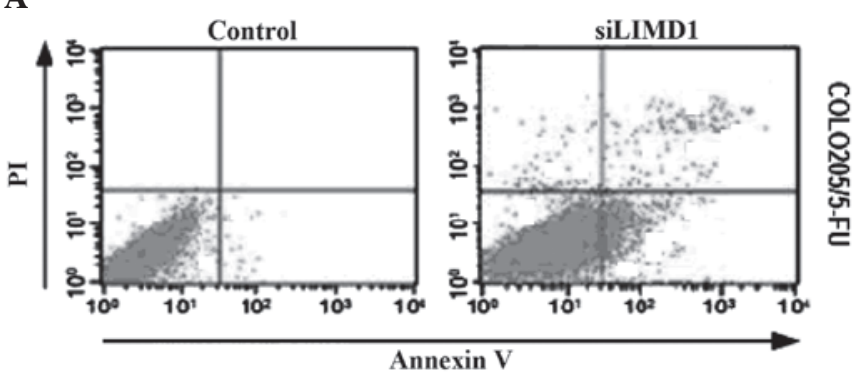

B

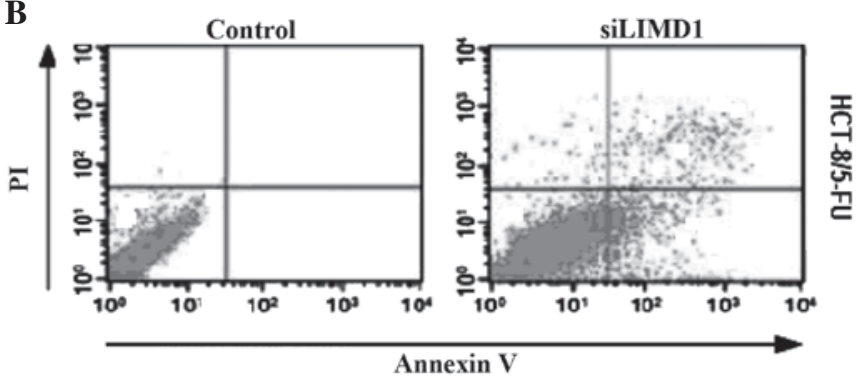

Figure 2. Apoptosis of multidrug resistance cells. The average percentage of apoptosis in the transfected cells was (A) $8.50 \%$ for Colo205/5-FU and (B) $8.11 \%$ for HCT-8/5-FU, which was significantly greater than that found in the non-transfected multidrug-resistant controls $[0.16 \%(\mathrm{P}=0.001)$ and $0.19 \%,(\mathrm{P}<0.05)$, respectively]. LIMD1, LIM domain-containing protein 1 ; 5-FU, 5-fluorouracil; PI, propidium iodide.

siRNA transfection decreases LIMD1 protein expression in MDR cells. Prior to inducing drug resistance in the Colo205 and HCT-8 cells, the LIMD1 protein levels were detectable; although, LIMD1 expression in the Colo205 and HCT-8 cells was relatively low (Fig. 1). As the CRC cell population developed with increasing MDR, LIMD1 protein expression was also found to significantly increase $(\mathrm{P}=0.006$ and $\mathrm{P}=0.002$ for LIMD1 in Colo205/5-FU and HCT-8/5-FU, respectively). Following siRNA transfection, the expression of the LIMD1 protein was reduced in MDR cells. In addition, LIMD1 protein expression was lower in the siRNA-transfected MDR cells than that in the parental controls.

Silencing LIMD1 reverses the MDR cell phenotype. The silencing of LIMD1 was found to enhance the chemosensitivity of the two MDR CRC sublines to 5-FU $(\mathrm{P}<0.001$; Table II).
Silencing LIMD1 induces apoptosis in 5-FU-resistant CRC cells. The average apoptotic rate in LIMD1 siRNA-transfected Colo205/5-FU and HCT-8/5-FU cells was 8.50 and $8.11 \%$, respectively (Fig. 2), which was significantly increased compared with that in the MDR sublines $[0.16 \%(\mathrm{P}=0.001)$ and $0.19 \%(\mathrm{P}<0.05)$, respectively].

\section{Discussion}

CRC responds poorly to chemotherapy owing to multidrug resistance, which contributes to poor treatment outcomes of $\mathrm{CRC}$ with chemotherapeutic drugs (7). However, a recent study demonstrated a close correlation between LIMD1 expression in CRCs (8). In the present study, the CRC Colo205 and HCT-8 cell lines were shown to express LIMD1, albeit at low levels, prior to 5-FU-induced multidrug resistance. As the CRC cells acquired increasing tolerance to 5-FU, LIMD1 expression was found to significantly increase in the Colo205 and HCT-8 MDR phenotypes. However, when the LIMD1 gene was silenced by siRNA, LIMD1 protein expression returned to levels comparable to those of the parental cell populations. The results of the current study indicated that the modulation of LIMD1 expression using RNA interference may reverse drug resistance in the CRC MDR phenotype.

The observation that the resistance of tumor cells to chemotherapy correlates with the overexpression of transport proteins, including LIMD1, has prompted efforts to develop agents with the ability to inhibit LIMD1-mediated drug transport (9). At present, no evidence exists to suggest that the inhibition of LIMD1 may reduce multidrug resistance in CRC. However, it has been reported that the suppression of the LIMD1 gene by RNA interference reverses the drug resistance in CRC cells (Colo205/5-FU and HCT-8/5-FU) (10). The results of the current study, derived from a similar CRC subline, showed that siRNA targeting LIMD1 effectively reverses MDR. This was demonstrated using chemosensitivity assays, and these results were as efficacious as blocking LIMD1. 5-FU and its analogs are widely used as first-line chemotherapeutic agents for patients with advanced CRC and these chemotherapeutics are known to function through various mechanisms $(11,12)$. It has been suggested that upregulated LIMD1 gene expression may be the major mechanism underlying acquired 5-FU resistance in CRC (13). In the context of the agents applied in the present study, the modulation of MRP1 expression was found to clearly sensitize the MDR CRC phenotype to chemotherapy. 
However, these observations raise the question of what mechanisms are involved in reversing the acquired drug resistance of CRC when LIMD1 is silenced. The results of the current study support this theory, as increased LIMD1 suppression was found to result in increased apoptosis.

In conclusion, the current study demonstrated that the suppression of LIMD1 expression may reverse drug resistance in the CRC MDR cells and enhance apoptosis. The results highlight the possibility that RNA interference targeting LIMD1 may be a useful approach in the treatment of CRC.

\section{Acknowledgements}

The current study was supported by the Foundations of Health Bureau (Xiamen, China; grant nos. 3502Z20124029 and 3502Z20134025) and the Medical Innovation Fund of Nanjing Military Command of Chinese PLA (grant no. MS090).

\section{References}

1. Levin TR and Corley DA: Colorectal-cancer screening - coming of age. N Engl J Med 369: 1164-1166, 2013.

2. Mastalier B, Tihon C, Ghiţă B, Botezatu C, Deaconescu V, Mandisodza P, Drăghici C and Simion S: Surgical treatment of colon cancer: Colentina surgical clinic experience. J Med Life 5: 348-353, 2012.

3. Ito Y, Yamada Y, Asada K, Ushijima T, Iwasa S, Kato K, Hamaguchi $\mathrm{T}$ and Shimada Y: EGFR L2 domain mutation is not correlated with resistance to cetuximab in metastatic colorectal cancer patients. J Cancer Res Clin Oncol 139: 1391-1396, 2013.

4. Zhu XS, Dai YC, Chen ZX, Xie JP, Zeng W, Lin YY and Tan QH: Knockdown of ECHS1 protein expression inhibits hepatocellular carcinoma cell proliferation via suppression of Akt activity. Crit Rev Eukaryot Gene Expr 23: 275-282, 2013.

5. Lin YL and Pasero P: Interference between DNA replication and transcription as a cause of genomic instability. Curr Genomics 13: $65-73,2012$.
6. Magge D, Zureikat AH, Bartlett DL, Holtzman MP, Choudry HA, Beumer JH, Pingpank JF, Holleran JL, Strychor S, Cunningham DE, et al: A phase I trial of isolated hepatic perfusion (IHP) using 5-FU and oxaliplatin in patients with unresectable isolated liver metastases from colorectal cancer.Ann Surg Oncol 20: 2180-2187, 2013.

7. Mirakhorli M, Rahman SA, Abdullah S, Vakili M, Rozafzon $\mathrm{R}$ and Khoshzaban A: Multidrug resistance protein 2 genetic polymorphism and colorectal cancer recurrence in patients receiving adjuvant FOLFOX-4 chemotherapy. Mol Med Rep 7: 613-617, 2013

8. Sharp TV, Munoz F, Bourboulia D, Presneau N, Darai E, Wang HW, Cannon M, Butcher DN, Nicholson AG, Klein $\mathrm{G}$, et al: LIM domains-containing protein 1 (LIMD1), a tumor suppressor encoded at chromosome $3 \mathrm{p} 21.3$, binds $\mathrm{pRB}$ and represses E2F-driven transcription. Proc Natl Acad Sci USA 101: 16531-16536, 2004.

9. Xu K, Liang X, Shen K, Sun L, Cui D, Zhao Y, Tian J, Ni L and Liu J: MiR-222 modulates multidrug resistance in human colorectal carcinoma by down-regulating ADAM-17. Exp Cell Res 318: 2168-2177, 2012.

10. Maddalena F, Laudiero G, Piscazzi A, Secondo A, Scorziello A, Lombardi V, Matassa DS, Fersini A, Neri V, Esposito F and Landriscina M: Sorcin induces a drug-resistant phenotype in human colorectal cancer by modulating $\mathrm{Ca}(2+)$ homeostasis. Cancer Res 71: 7659-7669, 2011.

11. Andersen V, Ostergaard M, Christensen J, Overvad K, Tjønneland A and Vogel U: Polymorphisms in the xenobiotic transporter Multidrug Resistance 1 (MDR1) and interaction with meat intake in relation to risk of colorectal cancer in a Danish prospective case-cohort study. BMC Cancer 9: 407, 2009.

12. Andersen V, Agerstjerne L, Jensen D, Østergaard M, Saebø M, Hamfjord J, Kure E and Vogel U: The multidrug resistance 1 (MDR1) gene polymorphism G-rs3789243-A is not associated with disease susceptibility in Norwegian patients with colorectal adenoma and colorectal cancer; a case control study. BMC Med Genet 10: 18, 2009.

13. Vilaça N, Amorim R, Machado AF, Parpot P, Pereira MF, Sardo M, Rocha J, Fonseca AM, Neves IC and Baltazar F: Potentiation of 5-fluorouracil encapsulated in zeolites as drug delivery systems for in vitro models of colorectal carcinoma. Colloids Surf B Biointerfaces 112: 237-244, 2013. 